\title{
Release Mathematical Model of Active Agent from Packaging Material into Food
}

\author{
Xiuling Huang, ${ }^{1}$ Heng Ye, ${ }^{1}$ and Kit L. Yam $^{2}$ \\ ${ }^{1}$ School of Mechatronics Engineering and Automation, Shanghai University, Shanghai 200072, China \\ ${ }^{2}$ School of Environment and Biological Sciences, Rutgers, The State University of New Jersey, NJ 08901, USA \\ Correspondence should be addressed to Xiuling Huang; xiulh@shu.edu.cn and Kit L. Yam; yam@aesop.rutgers.edu
}

Received 13 May 2013; Accepted 21 October 2013

Academic Editor: Vanee Chonhenchob

Copyright (c) 2013 Xiuling Huang et al. This is an open access article distributed under the Creative Commons Attribution License, which permits unrestricted use, distribution, and reproduction in any medium, provided the original work is properly cited.

\begin{abstract}
Active packaging is an innovative packaging technology by which active compounds are released from the package to enhance the quality and microbial safety for a wide range of foods. The problem of active ingredient release through the bilayer packaging food system is studied from a theoretical viewpoint. A release model is built to provide predictions of concentration and amount of active ingredient. The equations are built based on Fickian diffusion, and numerical solutions are obtained through finite difference. Different diffusion coefficients $D_{P}$ and $D_{C}$ of active ingredient in different packaging layers, partition coefficient $k_{C P}$ at the interface of outer layer and inner layer, partition coefficient $k_{F C}$ at the interface of inner layer and food, and mass transfer coefficient $h_{m}$ at the interface of inner layer and food are considered in the model. The effects of $k_{C P}$, thicknesses of outer layer and inner layer, $C_{P 0}$, $D_{P}, D_{C}, k_{F C}$, and $h_{m}$ on the release are discussed. Corresponding conclusions and analysis are given.
\end{abstract}

\section{Introduction}

The quality of food will be deteriorated during transport, processing, and storage through contamination, which occurs by growth of microorganisms, enzymatic or nonenzymatic chemical reactions [1]. In order to avoid deterioration and extend food shelf life, traditionally, active additives are mixed into initial food formulations to control microbial growth. However, this method is not always effective. Modern food packaging faces not only the requirements of food preservation and longer shelf life, but also the requirements of maintaining the fresh quality of nutrition, food additives, and preservatives "without addition" or at least "add less." So active packaging came into being. In recent years, there has been a great interest in active food packaging technologies. The aim of release systems intended for food packaging applications is to transfer the active agent from the packaging to the food in order to maintain a predetermined concentration of the active compound in the packed food for a determined period of time [2]. The release effect of active ingredient from packaging into food is better than the food surface dip or spray active compound. The method of dipping or spraying will induce the low effective concentration of active ingredients and then lose their activity. In order to make the active ingredient achieve better sustained release effect, the multilayer film has been widely used [3].

Recently, the experimental and migration research in this area have started [4-18], but the theoretical research is still deficient. Many researchers made release evaluation using the Crank modeling of migration of contaminants from packaging material into food [19-21]. But the migration model of bilayer packaging material only considers the complex of the same material and ignores the effect of critical interface, such as the partition at the interface of different material layer and the interface of material and food and the mass transfer of compound at the interface of material and food $[22,23]$. In fact, the problem of release in packaging material from different material complex is more complex than that in the packaging materials from identical material complex.

The objective of this study is to develop a theoretical model of release through a bilayer packaging system consisting of outer layer and inner layer into food. Unidirectional release, different diffusivities of active ingredient in outer layer and inner layer, partition coefficient at the interface of outer layer and inner layer, partition coefficient 


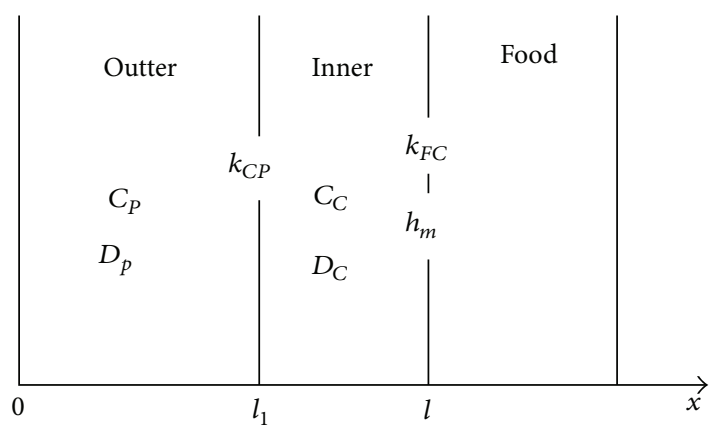

FIGURE 1: Scheme of the package-food system.

at the interface of inner layer and food, and mass transfer coefficient at the interface of inner layer and food are considered. Finite difference scheme is obtained. Factors which affect active ingredient concentration in outer layer and inner layer and release amount in inner layer and food are discussed.

\section{Theoretical Modeling}

The problem of release of active agent is highly complex; the following assumptions are made in order to make the process analyzed clearly regarding limited packaging and limited food.

2.1. Assumptions. The principal assumptions for model built are as follows. (1) The packaging material consists of two layers in perfect contact. One is outer layer with active ingredient in it, while the other is a virgin inner layer as shown in Figure 1. (2) The active agent is initially in the outer layer at a uniform concentration, while the inner layer is free from active ingredient. (3) The active ingredient releases through outer layer and inner layer and through the interface between the food and inner layer with a finite coefficient of mass transfer, $h_{m}$. There is no release of active agent through the external surface of the outer layer in contact with air. (4) The release of an active agent through the outer layer and inner layer is controlled by Fickian diffusion with constant diffusivities, which are $D_{P}$ for outer layer and $D_{C}$ for inner layer, respectively, (5) The partition coefficients, $k_{C P}$ and $k_{F C}$, of a compound are constant at the interface of outer layer and inner layer, inner layer and food. (6) There is no transfer of food to the packaging.

2.2. Mathematical Treatment. The one-dimensional diffusion through the packaging is expressed by Fick's equation with constant diffusivities in the outer layer and in the inner layer:

$$
\begin{array}{ll}
\frac{\partial C_{P}(x, t)}{\partial t}=D_{P} \frac{\partial^{2} C_{P}(x, t)}{\partial x^{2}}, & \left(0<x<l_{1}\right), \\
\frac{\partial C_{C}(x, t)}{\partial t}=D_{C} \frac{\partial^{2} C_{C}(x, t)}{\partial x^{2}}, & \left(l_{1}<x<l\right),
\end{array}
$$

where $C_{P}(x, t)$ and $C_{C}(x, t)$ are the concentrations of active agent in outer layer and inner layer, respectively, at position $x$

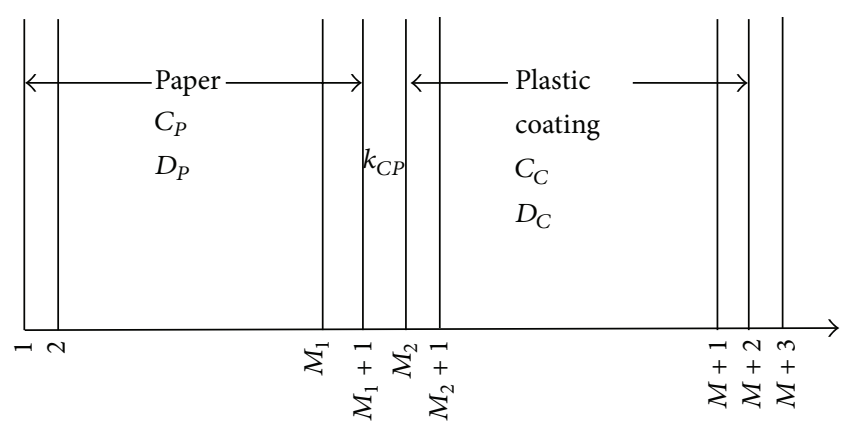

FIGURE 2: Scheme of meshing of bilayer packaging material.

and time $t, D_{P}$ and $D_{C}$ are the constant diffusivities of active ingredient in outer layer and inner layer, respectively, and $l_{1}$ and $l_{2}=l-l_{1}$ are the thickness of outer layer and inner layer, respectively.

The initial conditions are

$$
\begin{aligned}
& t=0, \\
& 0<x<l_{1}, \quad C_{P}=C_{P 0}, \\
& l_{1}<x<l, \quad C_{C}=0,
\end{aligned}
$$

where $C_{P 0}$ is the initial concentration of active ingredient in outer layer.

The boundary conditions express the fact that there is no external transfer at $x=0$; the flux of active compound is continuous whereas the concentration itself is discontinuous at $x=l_{1}$

$$
\begin{aligned}
& t>0, \\
& x=0, \quad \frac{\partial C_{P}}{\partial x}=0, \\
& x=l_{1}, \quad D_{P} \frac{\partial C_{P}(x, t)}{\partial x}=D_{C} \frac{\partial C_{C}(x, t)}{\partial x}, \\
& x=l_{1}, \quad C_{C}=k_{C P} C_{P}, \\
& x=l, \quad-D_{C} \frac{\partial C_{C}(x, t)}{\partial x}=h_{m}\left(C_{C}-\frac{C_{F}}{k_{F C}}\right),
\end{aligned}
$$

where $k_{C P}$ and $k_{F C}$ are the constant partition coefficients of active ingredient at the interface of outer layer and inner layer, inner layer and food. $h_{m}$ is the constant mass transfer coefficient of active ingredient at the interface of inner layer and food.

The grid is divided for the composite packaging material in thickness direction. And $l$ is divided into $M$ parts (space step is $h$ ); release time $T$ is divided into $n$ parts (time step is $\tau$ ). Here, the interface of outer layer and inner layer is separated for the convenience of simulation. Wherein $1, M_{1}, M_{2}, M+2$, $M+3$ indicate the left margin of outer layer, right margin of outer layer, left margin of inner layer, interface of inner layer and food, and active agent concentration in food, respectively. In fact, both $M_{1}$ and $M_{2}$ are in the $x=l_{1}$ on the dimension. The meshing of bilayer packaging material divided in the thickness direction is shown in Figure 2. 
The following signs are introduced [24, 25]:

$$
\begin{aligned}
C_{i}^{k-(1 / 2)}= & \frac{1}{2}\left(C_{i}^{k}+C_{i}^{k+1}\right), \quad C_{i-(1 / 2)}^{k}=\frac{1}{2}\left(C_{i}^{k}+C_{i-1}^{k}\right), \\
\sigma_{t} C_{i}^{k-(1 / 2)}= & \frac{1}{\tau}\left(C_{i}^{k}-C_{i}^{k-1}\right), \quad \sigma_{x} C_{i-(1 / 2)}^{k}=\frac{1}{h}\left(C_{i}^{k}-C_{i-1}^{k}\right), \\
& \sigma_{x}^{2} C_{i}^{k}=\frac{1}{h}\left(\sigma_{x} C_{i+(1 / 2)}^{k}-\sigma_{x} C_{i-(1 / 2)}^{k}\right) .
\end{aligned}
$$

Equations (1)-(3) can be converted into the following formula:

$$
\begin{aligned}
& \frac{1}{2} \sigma_{t} C_{P i-(1 / 2)}^{k-(1 / 2)}+\frac{1}{2} \sigma_{t} C_{P i+(1 / 2)}^{k-(1 / 2)}-D_{P} \sigma_{x}^{2} C_{P i}^{k-(1 / 2)}=0, \\
& 2 \leq i \leq M_{1}, \quad 1 \leq k \leq N, \\
& \frac{1}{2} \sigma_{t} C_{C i-(1 / 2)}^{k-(1 / 2)}+\frac{1}{2} \sigma_{t} C_{C_{i+(1 / 2)}^{k-(1 / 2)}}^{k-} D_{C} \sigma_{x}^{2} C_{C i}^{k-(1 / 2)}=0, \\
& M_{2}+1 \leq i \leq M+1, \quad 1 \leq k \leq N, \\
& C_{P_{i}}^{0}=C_{P 0}, \quad 1 \leq i \leq M_{1}+1, \\
& C_{C i}^{0}=0, \quad M_{2} \leq i \leq M+2, \\
& \sigma_{t} C_{P 1+(1 / 2)}^{k-(1 / 2)}=\frac{2 D_{P}}{h} \sigma_{x} C_{P 1+(1 / 2)}^{k-(1 / 2)}, \quad 1 \leq k \leq N, \\
& \sigma_{t} C_{P M_{1}+(1 / 2)}^{k-(1 / 2)}=\frac{2 D_{C}}{h} \sigma_{x} C_{C M_{2}}^{k-(1 / 2)}-\frac{2 D_{P}}{h} \sigma_{x} C_{P M_{1}+(1 / 2)^{\prime}}^{k-(1 / 2)} \\
& 1 \leq k \leq N \text {, } \\
& \sigma_{t} C_{C M_{2}+(1 / 2)}^{k-(1 / 2)}=\frac{2 D_{C}}{h} \sigma_{x} C_{C M_{2}+(1 / 2)}^{k-(1 / 2)}-\frac{2 D_{P}}{h} \sigma_{x} C_{P M_{1}}^{k-(1 / 2)} \text {, } \\
& 1 \leq k \leq N, \\
& C_{C M_{2}}^{k-(1 / 2)}=k_{C P} C_{P M_{1}+1}^{k-(1 / 2)}, \quad 1 \leq k \leq N, \\
& \sigma_{t} C_{C M+2-(1 / 2)}^{k-(1 / 2)}+\frac{h_{m}}{h}\left(C_{C M+2}^{k-(1 / 2)}-\frac{C_{F}^{k-(1 / 2)}}{k_{F C}}\right) \\
& +\frac{D_{C}}{h} \sigma_{x} C_{C M+1}^{k-(1 / 2)}=0, \quad 1 \leq k \leq N, \\
& C_{F}{ }^{k}=\frac{C_{P 0} V_{P}-M_{P}^{k}-M_{C}^{k}}{V_{F}}, \quad 1 \leq k \leq N .
\end{aligned}
$$

The corresponding finite difference scheme is as follows:

$$
\begin{array}{r}
\left(1-r_{1}\right) C_{P i-1}^{k}+\left(2+2 r_{1}\right) C_{P i}^{k}+\left(1-r_{1}\right) C_{P i+1}^{k} \\
=\left(1+r_{1}\right) C_{P i-1}^{k-1}+\left(2-2 r_{1}\right) C_{P i}^{k-1}+\left(1+r_{1}\right) C_{P i+1}^{k-1}, \\
2 \leq i \leq M_{1}, \quad 1 \leq k \leq N,
\end{array}
$$

$$
\begin{array}{r}
\left(1-r_{2}\right) C_{C i-1}^{k}+\left(2+2 r_{2}\right) C_{C i}^{k}+\left(1-r_{2}\right) C_{C i+1}^{k} \\
=\left(1-r_{2}\right) C_{C i-1}^{k-1}+\left(2+2 r_{2}\right) C_{C i}^{k-1}+\left(1-r_{2}\right) C_{C i+1}^{k-1}, \\
M_{2}+1 \leq i \leq M+1, \quad 1 \leq k \leq N
\end{array}
$$

initial conditions

$$
\begin{gathered}
C_{P i}^{0}=C_{P 0}, \quad 1 \leq i \leq M_{1}+1, \\
C_{C_{i}}^{0}=0, \quad M_{2} \leq i \leq M+2,
\end{gathered}
$$

boundary conditions

$$
\begin{aligned}
& \left(1+r_{1}\right) C_{P 1}^{k}+\left(1-r_{1}\right) C_{P 2}^{k} \\
& =\left(1-r_{1}\right) C_{P 1}^{k-1}+\left(1+r_{1}\right) C_{P 2}^{k-1}, \quad 1 \leq k \leq N, \\
& \left(1-r_{1}\right) C_{P M_{1}}^{k}+\left(1+r_{1}\right) C_{P M_{1}+1}^{k}+r_{2} C_{C M_{2}}^{k}-r_{2} C_{C M_{2}+1}^{k} \\
& =\left(1+r_{1}\right) C_{P M_{1}}^{k-1}+\left(1-r_{1}\right) C_{P M_{1}+1}^{k-1} \\
& -r_{2} C_{C M_{2}}^{k-1}+r_{2} C_{C M_{2}+1}^{k-1}, \quad 1 \leq k \leq N, \\
& -r_{1} C_{P M_{1}}^{k}+r_{1} C_{P M_{1}+1}^{k}+\left(1+r_{2}\right) C_{C M_{2}}^{k}+\left(1-r_{2}\right) C_{C M_{2}+1}^{k} \\
& =r_{1} C_{P M_{1}}^{k-1}-r_{1} C_{P M_{1}+1}^{k-1}+\left(1-r_{2}\right) C_{C M_{2}}^{k-1} \\
& +\left(1+r_{2}\right) C_{C M_{2}+1}^{k-1}, \quad 1 \leq k \leq N, \\
& C_{C M_{2}}^{k}=k_{C P} C_{P M_{1}}^{k}, \quad 1 \leq k \leq N, \\
& \left(1-\frac{1}{2} r_{2}\right) C_{C M+1}^{k}+\left(1+\frac{1}{2} r_{2}+\frac{h_{m} \tau}{h}\right) C_{C M+2}^{k}-\frac{h_{m} \tau}{h k_{F C}} C_{F}^{k} \\
& =\left(1+\frac{1}{2} r_{2}\right) C_{C M+1}^{k-1}+\left(1-\frac{1}{2} r_{2}-\frac{h_{m} \tau}{h}\right) C_{C M+2}^{k-1} \\
& +\frac{h_{m} \tau}{h k_{F C}} C_{F}^{k-1}, \quad 1 \leq k \leq N, \\
& \frac{1}{4} h C_{1}^{k}+\frac{1}{2} h \sum_{i=2}^{M_{1}-1} C_{i}^{k}+\frac{1}{4} h C_{M_{1}}^{k}+\frac{1}{4} h C_{M_{2}}^{k} \\
& +\frac{1}{2} h \sum_{i=M_{2}+1}^{M+2} C_{i}^{k}+\frac{1}{4} h C_{M+2}^{k}+\frac{1}{2} V_{F} C_{F}^{k} \\
& =-\frac{1}{4} h C_{1}^{k-1}-\frac{1}{2} h \sum_{i=2}^{M_{1}-1} C_{i}^{k-1}-\frac{1}{4} h C_{M_{1}}^{k-1} \\
& -\frac{1}{4} h C_{M_{2}}^{k-1}-\frac{1}{2} h \sum_{i=M_{2}+1}^{M+2} C_{i}^{k-1}-\frac{1}{4} h C_{M+2}^{k-1} \\
& -\frac{1}{2} V_{F} C_{F}^{k-1}+C_{P 0} V_{P}, \quad 1 \leq k \leq N,
\end{aligned}
$$

where $r_{1}=2 D_{P} \tau / h^{2}, r_{2}=2 D_{C} \tau / h^{2}$. 


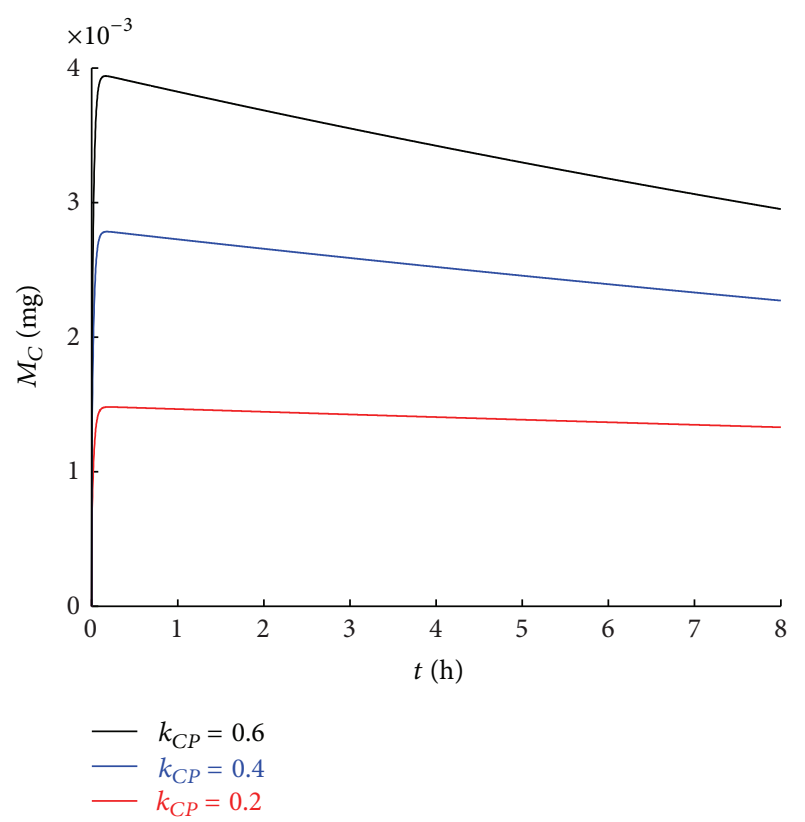

FIGURE 3: Release kinetics of active ingredient into inner layer for various values of $k_{C P}\left(l_{1}=48 \mu \mathrm{m}, l_{2}=16 \mu \mathrm{m}, C_{P 0}=5 \mathrm{mg} \cdot \mathrm{cm}^{-3}\right.$, $k_{F C}=0.2$, and $A=1 \mathrm{~cm}^{2}$ ).

\section{Results and Discussions}

The previously mentioned finite difference scheme is converted into the form of $A C^{k}=B C^{k-1}+D$; here, $A$ and $B$ are $M+3$-dimensional square and $C^{k}, C^{k-1}$, and $D$ are one-dimensional vector. The numerical solutions are received through iterative calculation. And the effect of parameters, such as $k_{C P}, l_{1}, l_{2}, D_{P}, D_{C}, C_{P 0}, h_{m}, k_{F C}$, on concentration and amount of active agent in packaging and food is discussed. Here, the values of diffusivities $D_{P}$ and $D_{C}$, mass transfer coefficient $h_{m}$ are $10^{-4}, 10^{-8}$, and $10^{-7}$, respectively in order to facilitate analysis.

3.1. Release Kinetics of Active Ingredient into Inner Layer and Food for Various Values of $k_{C P}$ and Profiles of Active Ingredient Concentration through the Packaging for Various Values of $k_{C P}$. The definition of $k_{C P}$ is the ratio of the concentration of active agent in inner layer to the concentration of the active agent in outer layer at release equilibrium. The release kinetics and the concentration profiles are shown in Figures 3-6 for various values of $k_{C P}$.

These Figures 3-6 lead to the following conclusions about the influences of the partition coefficient on the interface of outer layer and inner layer.

(1) Release kinetics of active ingredient into inner layer and food are drawn for various values of $k_{C P}$ in Figures 3 and 4 . The amounts of active ingredient in inner layer and food increase with $k_{C P}$. This phenomenon can be understood according to the definition of $k_{C P}$. The greater the $k_{C P}$, the more active ingredient in inner layer for the identical active compound amount in outer layer. Meanwhile, the amounts of active ingredient will inevitably increase in food.

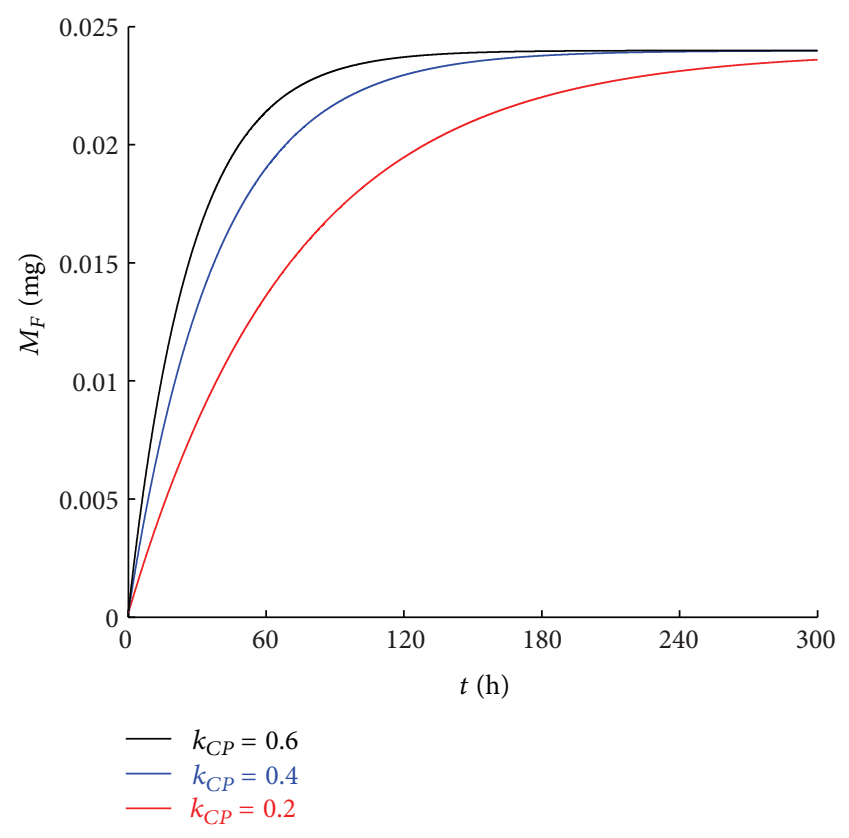

FIGURE 4: Release kinetics of active ingredient into food for various values of $k_{C P}\left(l_{1}=48 \mu \mathrm{m}, l_{2}=16 \mu \mathrm{m}, k_{F C}=0.2, A=1 \mathrm{~cm}^{2}\right.$, and $\left.C_{P 0}=5 \mathrm{mg} \cdot \mathrm{cm}^{-3}\right)$.

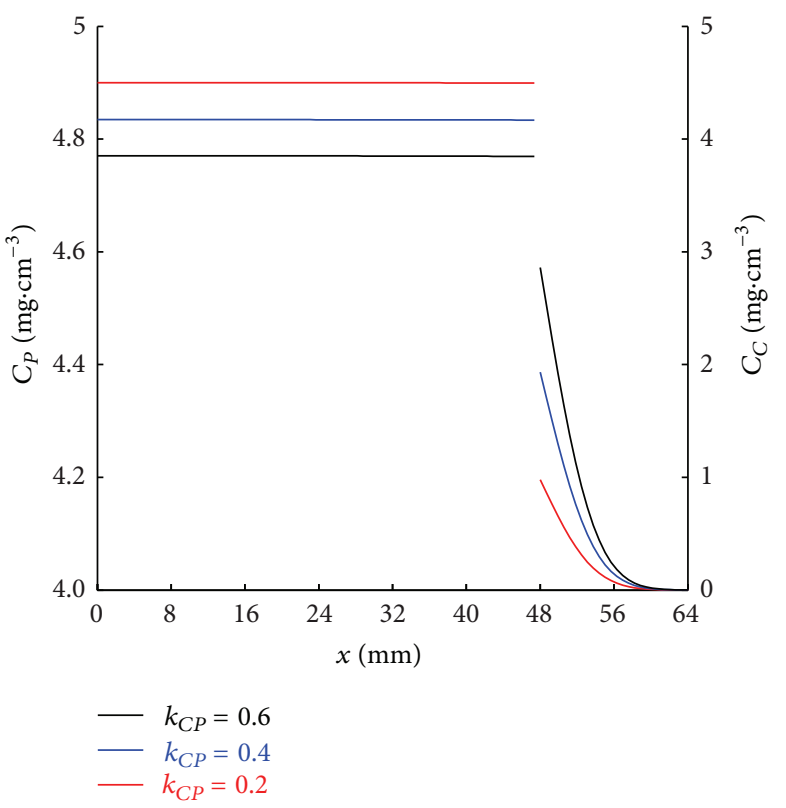

FIgURE 5: Profiles of active ingredient concentration through the packaging for various values of $k_{C P}\left(l_{1}=48 \mu \mathrm{m}, l_{2}=16 \mu \mathrm{m}\right.$, $k_{F C}=0.2, C_{P 0}=5 \mathrm{mg} \cdot \mathrm{cm}^{-3}$, and $\left.t=10 \mathrm{~s}\right)$.

(2) The concentration profiles are drawn using different concentration coordinates, with various values of $k_{C P}$ ranging from 0.2 to 0.6 and different release time in Figures 5 and 6. It can be seen that the distribution of concentration of active compound at the interface is in accordance with the definition of $k_{C P}$. 


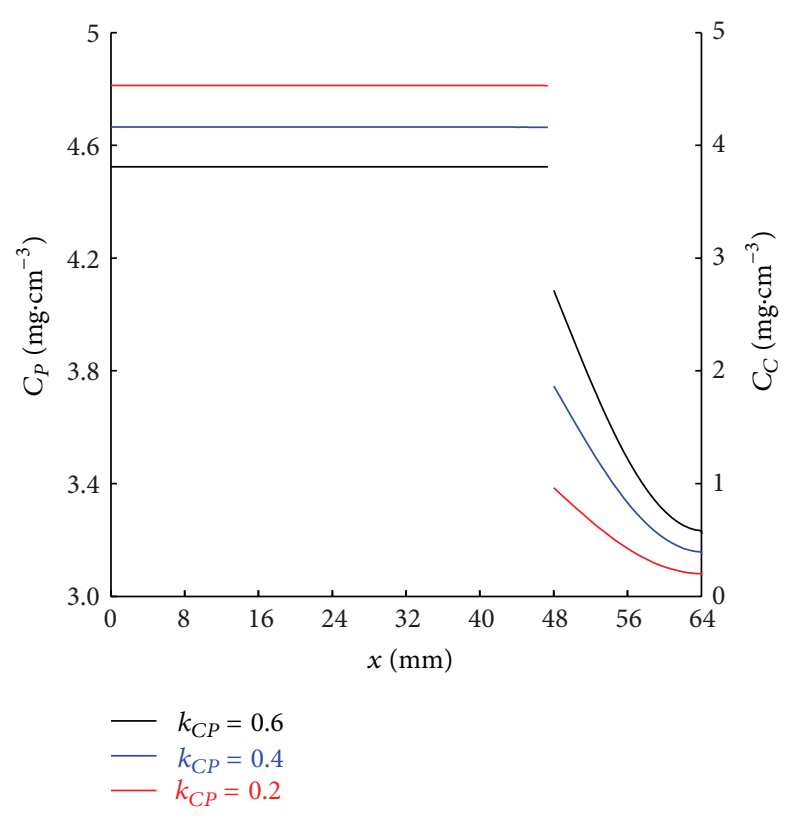

Figure 6: Profiles of active ingredient concentration through the packaging for various values of $k_{C P}\left(l_{1}=48 \mu \mathrm{m}, l_{2}=16 \mu \mathrm{m}\right.$, $k_{F C}=0.2, C_{P 0}=5 \mathrm{mg} \cdot \mathrm{cm}^{-3}$, and $\left.t=50 \mathrm{~s}\right)$.

(3) According to Figures 5 and 6, at the interface of inner layer and food, the active ingredient does not instantly release into the food. The active ingredient accumulates in inner layer and then releases to food with the increase of time. It can reveal that mass transfer coefficient $h_{m}$ and partition coefficient $k_{F C}$ at the interface of inner layer and food hinder the release of active ingredient from packaging material to food.

\subsection{Release Kinetics of Active Ingredient into Inner Layer} and Food for Various Thicknesses of Outer Layer and Inner Layer. In order to learn clearly the effect of thickness, it is necessary to study the release kinetics of active ingredient for various thicknesses of outer layer and inner layer. These kinetics graphs are shown in Figures 7-10. The amounts of active ingredient in inner layer and food are expressed in terms of time. The comments are as follows.

(1) When the initial concentration of active ingredient in outer layer, the value of $k_{C P}, k_{F C}$, and the thickness of inner layer are constant, the amounts of active ingredient releasing into inner layer and food increase obviously with the increase of the thickness of outer layer as shown in Figures 7 and 8 . There is a positive correlation between the amount of active ingredient in food and outer layer thickness. For the same initial concentration of active ingredient in outer layer, thicker outer layer means higher amount of active ingredient in outer layer.

(2) When the initial concentration of active ingredient in outer layer, the value of $k_{C P}, k_{F C}$, and the thickness of outer layer are constant, the amounts of active ingredient in the food decrease obviously with the increase of the thickness of inner layer, as shown in Figures 9 and 10. Correspondingly,

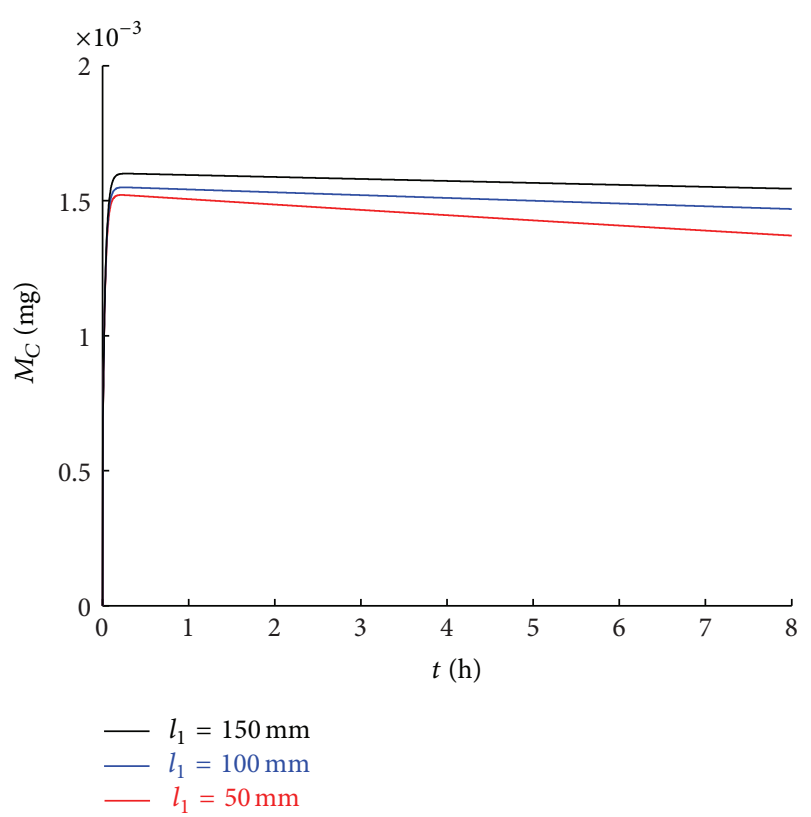

FIGURE 7: Release kinetics of active ingredient into inner layer for various thicknesses of outer layer $\left(l_{2}=16 \mu \mathrm{m}, C_{P 0}=5 \mathrm{mg} \cdot \mathrm{cm}^{-3}\right.$, $k_{C P}=0.2, k_{F C}=0.2$, and $\left.A=1 \mathrm{~cm}^{2}\right)$.

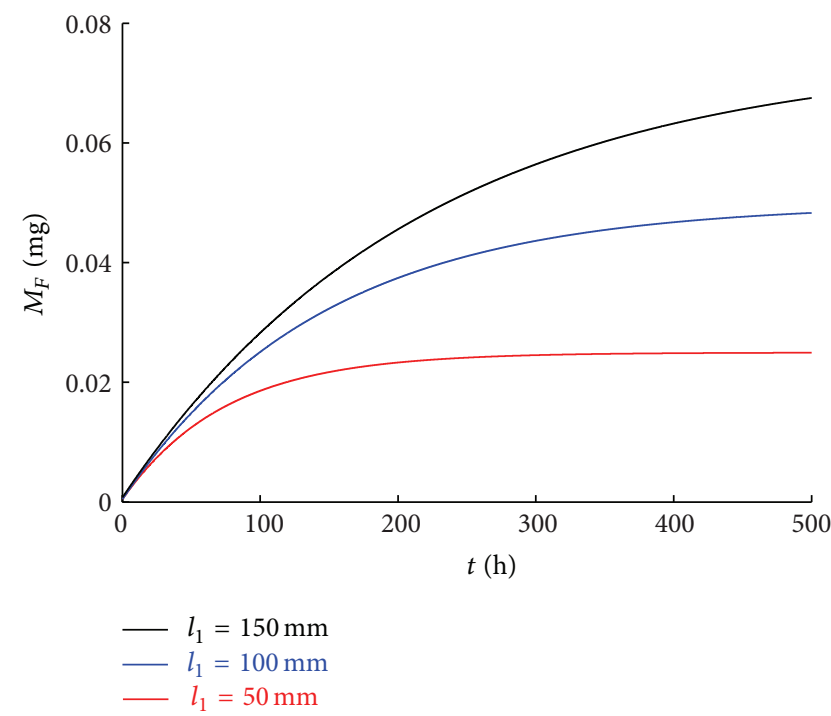

FIGURE 8: Release kinetics of active ingredient into food for various thicknesses of outer layer $\left(l_{2}=16 \mu \mathrm{m}, C_{P 0}=5 \mathrm{mg} \cdot \mathrm{cm}^{-3}, k_{C P}=0.2\right.$, $k_{F C}=0.2$, and $A=1 \mathrm{~cm}^{2}$ ).

the residue of the active ingredient in inner layer is more, which means release rate of active ingredient into food depending on the thickness of inner layer.

3.3. Release Kinetics of Active Ingredient into Inner Layer and Food for Various $C_{P 0}$. The root cause of release is the presence of a certain initial concentration of active ingredient. There is a necessary link between active ingredient content in food and the initial active ingredient concentration in packaging 


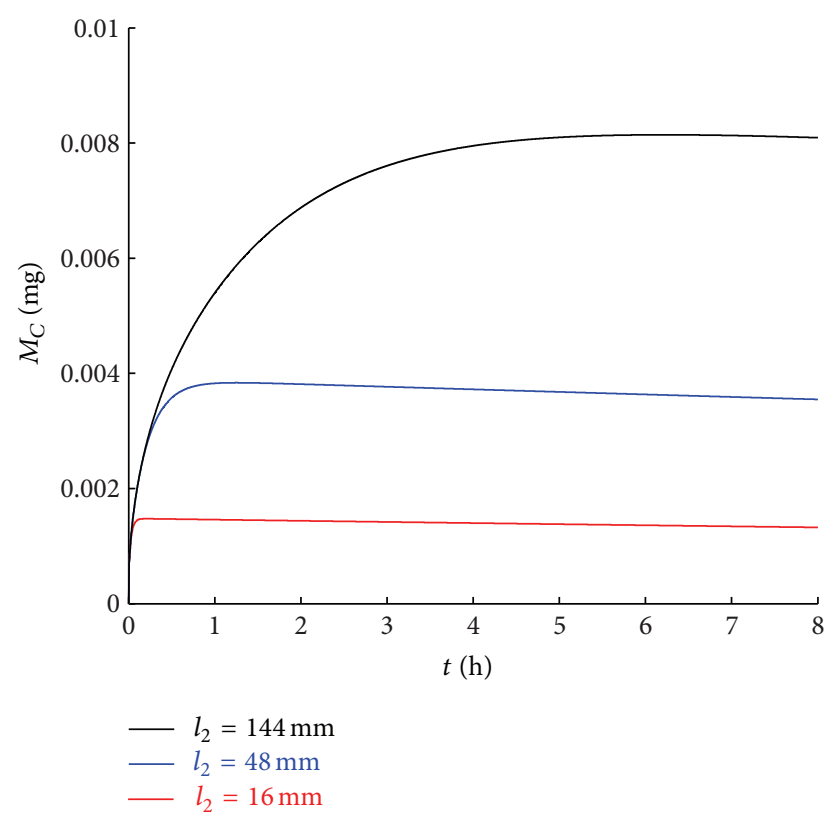

FIGURE 9: Release kinetics of active ingredient into inner layer for various thicknesses of inner layer $\left(l_{1}=48 \mu \mathrm{m}, C_{P 0}=5 \mathrm{mg} \cdot \mathrm{cm}^{-3}\right.$, $\left.k_{C P}=0.2, k_{F C}=0.2, A=1 \mathrm{~cm}^{2}\right)$.

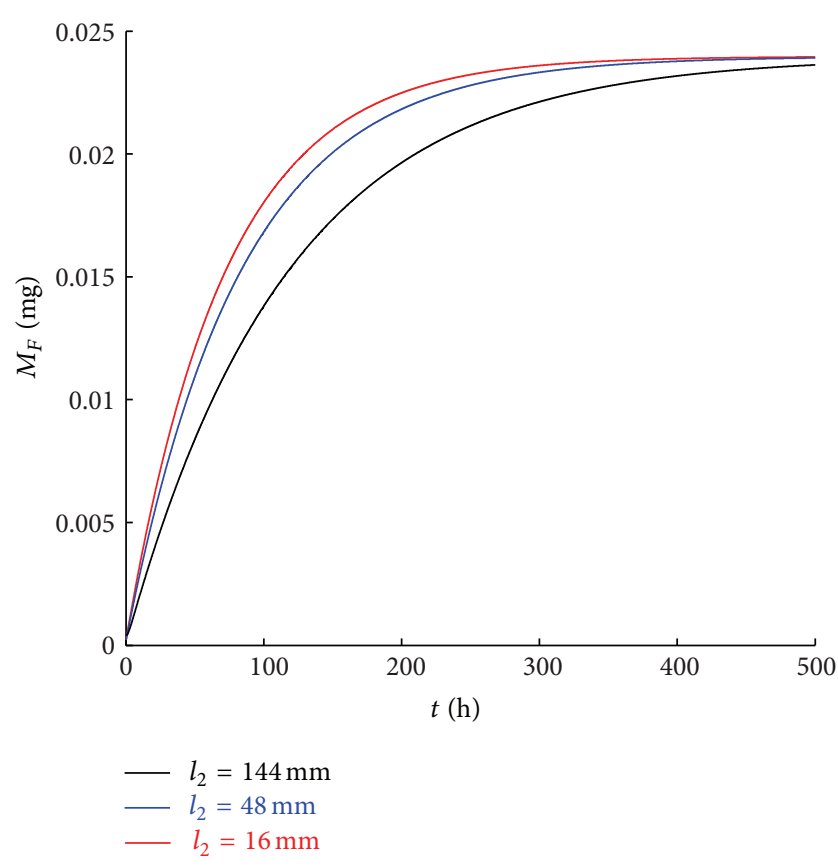

FIGURE 10: Release kinetics of active ingredient into food for various thicknesses of inner layer $\left(l_{1}=48 \mu \mathrm{m}, C_{P 0}=5 \mathrm{mg} \cdot \mathrm{cm}^{-3}, k_{C P}=0.2\right.$, $k_{F C}=0.2$, and $A=1 \mathrm{~cm}^{2}$ ).

material. According to Figures 11 and 12, the active ingredient amounts in material inner layer and food increase with the increase of active ingredient initial concentration in material outer layer when the release equilibrium is reached. So, it can achieve protecting food by controlling the active ingredient initial concentration in outer packaging material.

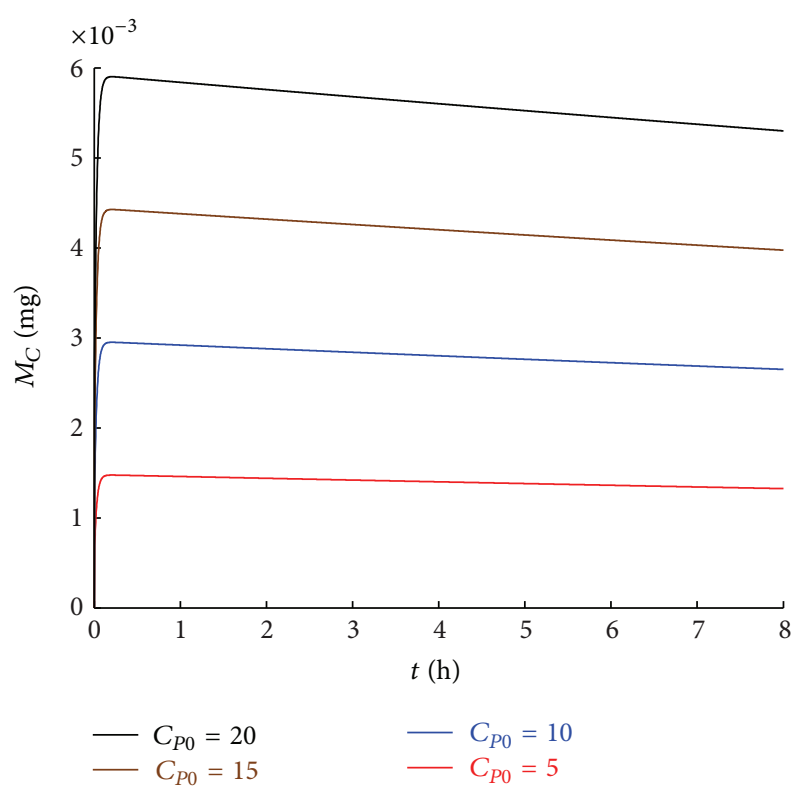

FIGURE 11: Release kinetics of active ingredient into inner layer for various $C_{P 0}\left(l_{1}=48 \mu \mathrm{m}, l_{2}=16 \mu \mathrm{m}, k_{C P}=0.2, k_{F C}=0.2, A=\right.$ $\left.1 \mathrm{~cm}^{2}\right)$.

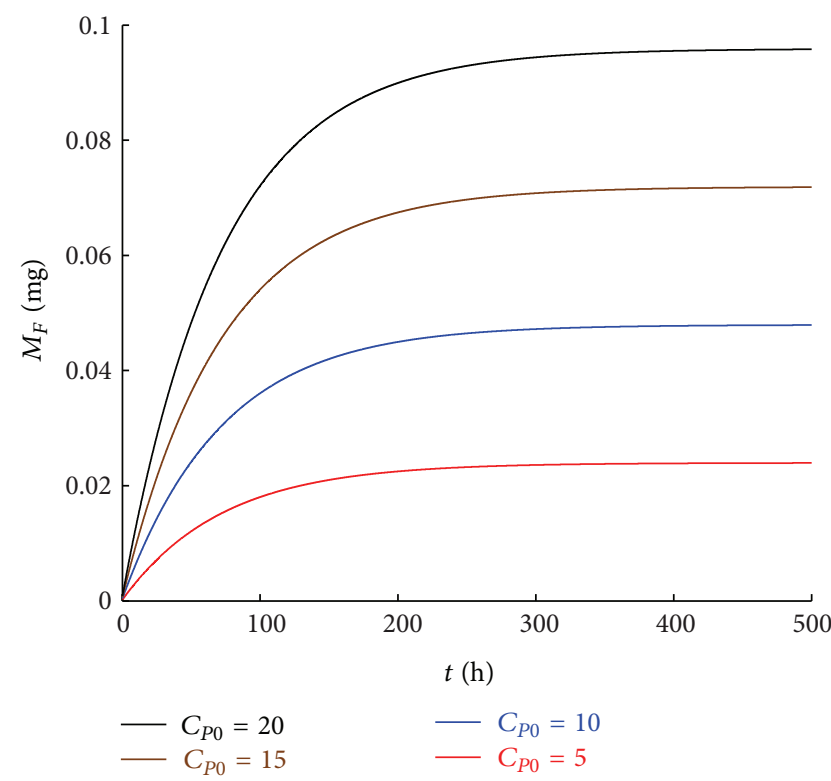

FIGURE 12: Release kinetics of active ingredient into food for various $C_{P 0}\left(l_{1}=48 \mu \mathrm{m}, l_{2}=16 \mu \mathrm{m}, k_{C P}=0.2, k_{F C}=0.2\right.$, and $\left.A=1 \mathrm{~cm}^{2}\right)$.

3.4. Release Kinetics of Active Ingredient into Inner Layer and Food for Various $D_{P}$ and $D_{C}$. Diffusion coefficient is one of the most important parameters in the release process of active ingredient. It is related to physical and chemical properties of the packaging material itself, the active ingredient property, food property, temperature, and other factors. Diffusion coefficient significantly affects the amount of active ingredient in material and food. Here partition coefficients $k_{C P}$ and $k_{F C}$ are assumed as a fixed value. Figures 13 and 14 


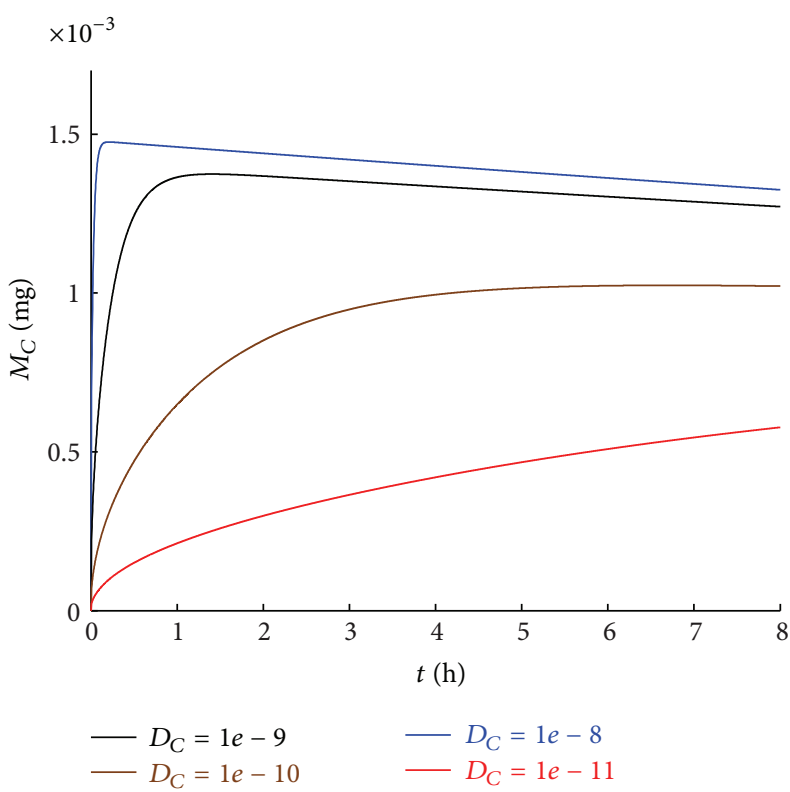

FIGURE 13: Release kinetics of active ingredient into inner layer for various $D_{C}\left(l_{1}=48 \mu \mathrm{m}, l_{2}=16 \mu \mathrm{m}, k_{C P}=0.2, k_{F C}=0.2, A=1 \mathrm{~cm}^{2}\right.$, and $C_{P 0}=5 \mathrm{mg} \cdot \mathrm{cm}^{-3}$ ).

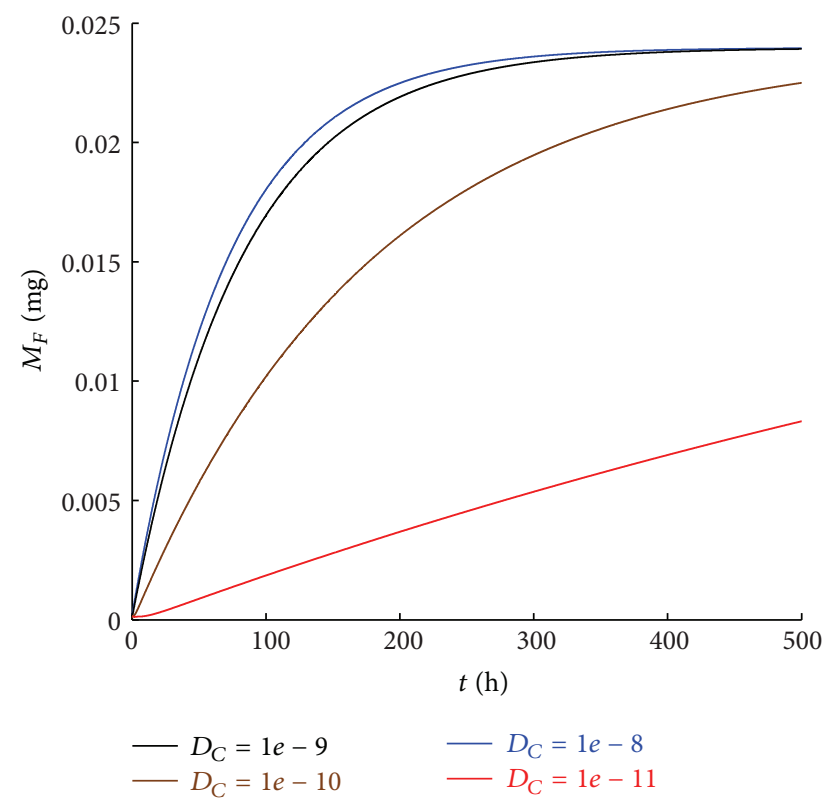

FIGURE 14: Release kinetics of active ingredient into food for various $D_{C}\left(l_{1}=48 \mu \mathrm{m}, l_{2}=16 \mu \mathrm{m}, k_{C P}=0.2, k_{F C}=0.2, A=1 \mathrm{~cm}^{2}\right.$, and $\left.C_{P 0}=5 \mathrm{mg} \cdot \mathrm{cm}^{-3}\right)$.

are the effect diagrams when inner layer diffusion coefficient $D_{C}$ changes and outer layer diffusion coefficient $D_{P}$ keeps constant. Figures 15 and 16 are the effect diagrams when outer layer diffusion coefficient $D_{P}$ changes and inner layer diffusion coefficient $D_{C}$ keeps constant. The results show that the change of inner layer diffusion coefficient $D_{C}$ plays a major role. Release rate of active ingredient improves significantly with the increase of the magnitude of $D_{C}$, and

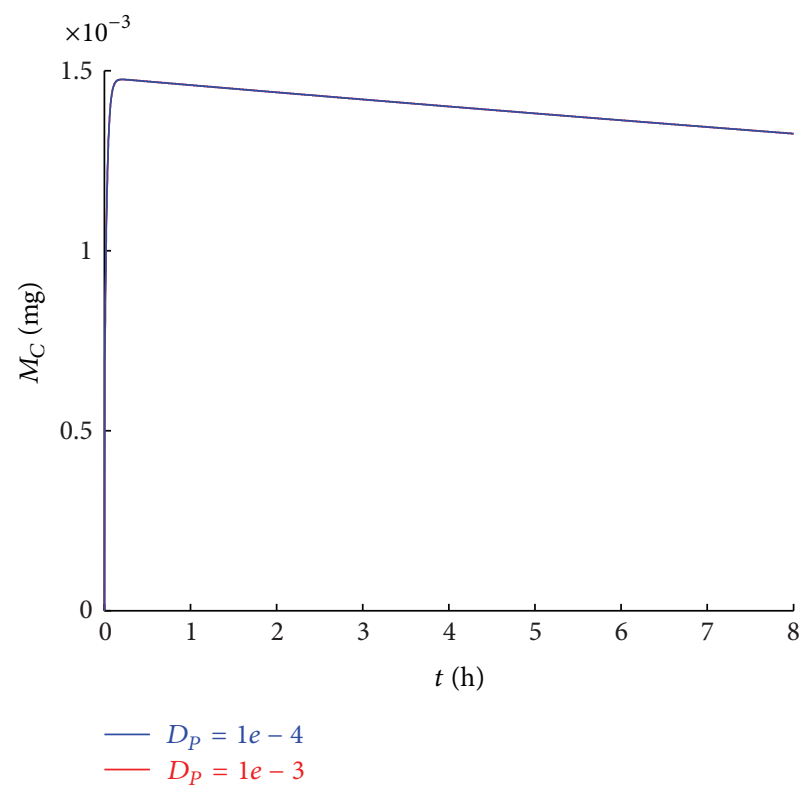

FIGURE 15: Release kinetics of active ingredient into inner layer for various $D_{P}\left(l_{1}=48 \mu \mathrm{m}, l_{2}=16 \mu \mathrm{m}, k_{C P}=0.2, k_{F C}=0.2, A=1 \mathrm{~cm}^{2}\right.$, and $C_{P 0}=5 \mathrm{mg} \cdot \mathrm{cm}^{-3}$ ).

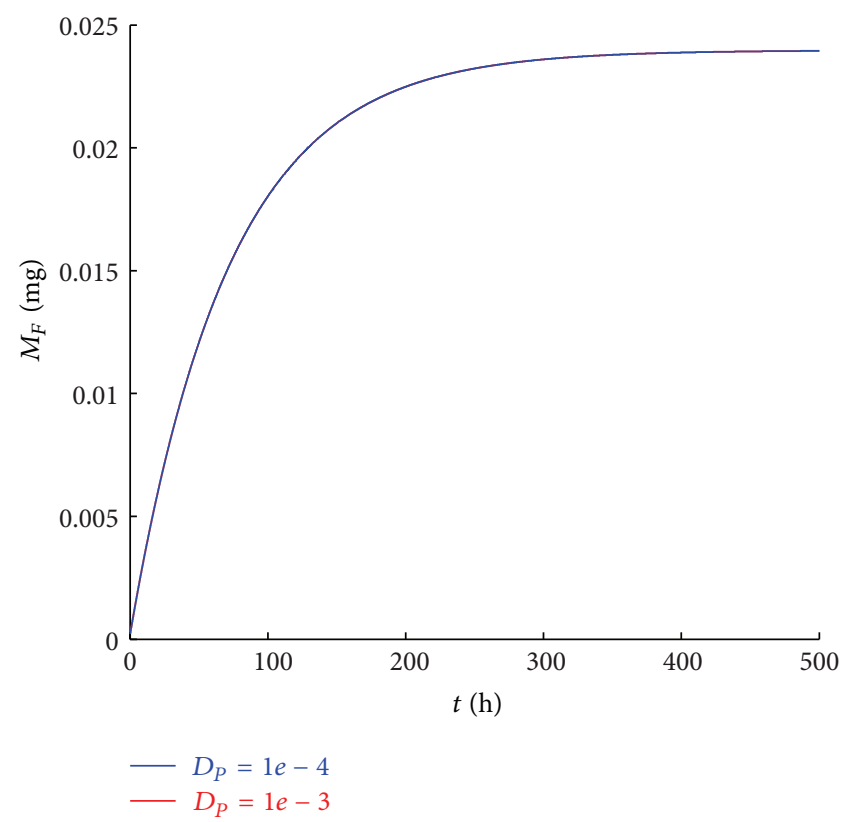

FIGURE 16: Release kinetics of active ingredient into food for various $D_{P}\left(l_{1}=48 \mu \mathrm{m}, l_{2}=16 \mu \mathrm{m}, k_{C P}=0.2, k_{F C}=0.2, A=1 \mathrm{~cm}^{2}\right.$, and $\left.C_{P 0}=5 \mathrm{mg} \cdot \mathrm{cm}^{-3}\right)$.

it has a great sensitivity of $D_{C}$. However, the effect of $D_{P}$ on release rate is not significant. This shows that the property of inner layer packaging material has a great effect on release rate of active ingredient under certain other conditions.

3.5. Release Kinetics of Active Ingredient into Inner Layer and Food for Various $h_{m}$. Mass transfer coefficient $h_{m}$ 


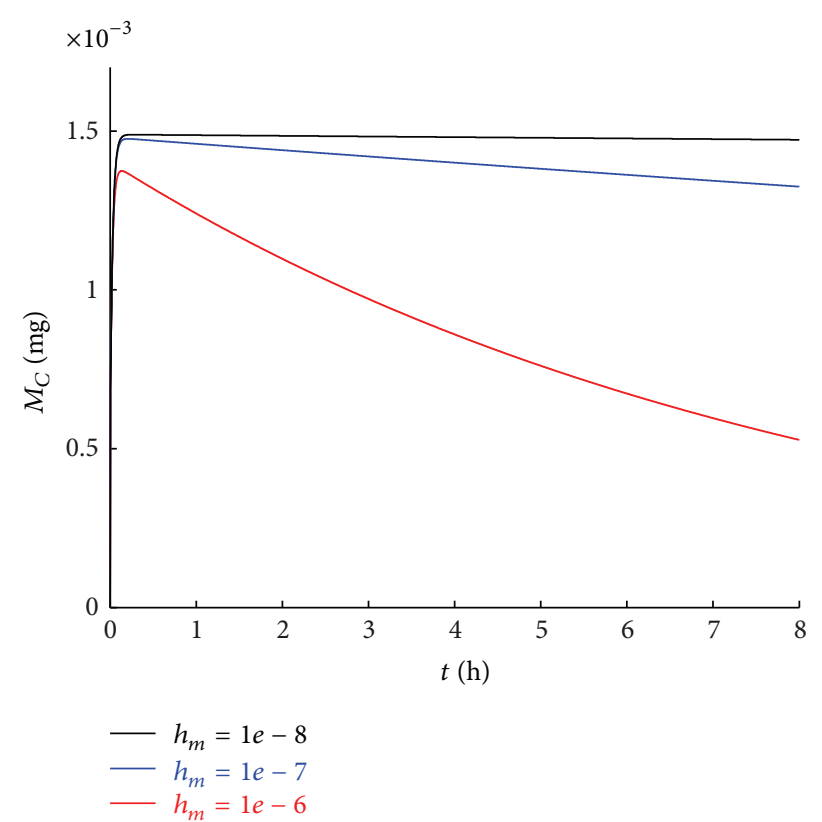

FIGURE 17: Release kinetics of active ingredient into inner layer for various $h_{m}\left(l_{1}=48 \mu \mathrm{m}, l_{2}=16 \mu \mathrm{m}, k_{C P}=0.2, k_{F C}=0.2, A=1 \mathrm{~cm}^{2}\right.$, and $C_{P 0}=5 \mathrm{mg} \cdot \mathrm{cm}^{-3}$ ).

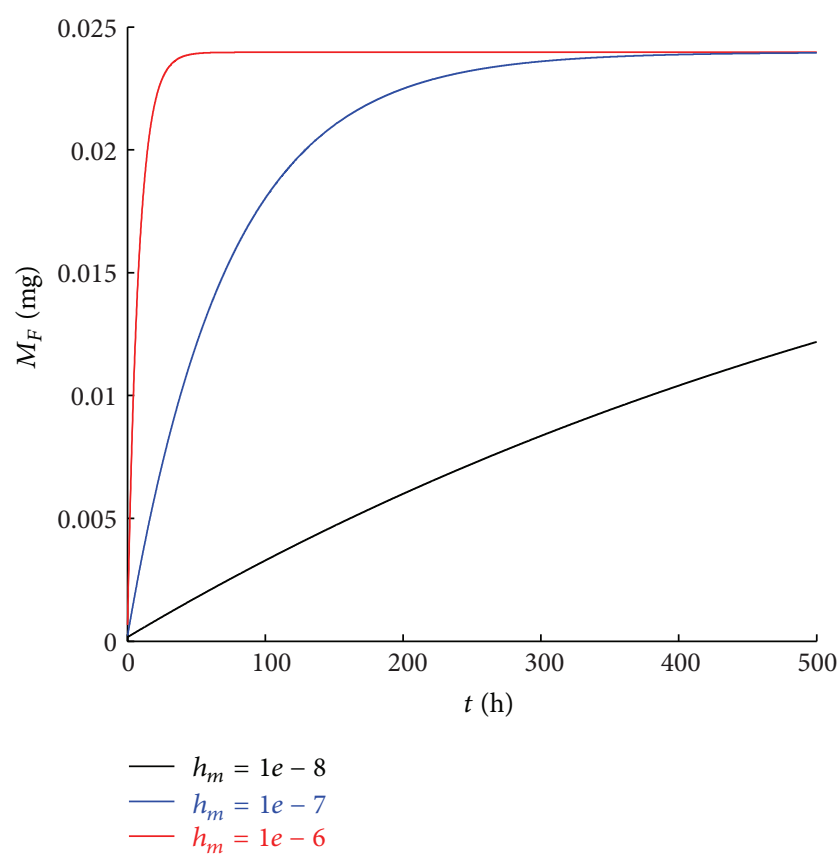

FIGURE 18: Release kinetics of active ingredient into food for various $h_{m}\left(l_{1}=48 \mu \mathrm{m}, l_{2}=16 \mu \mathrm{m}, k_{C P}=0.2, k_{F C}=0.2, A=1 \mathrm{~cm}^{2}\right.$, and $\left.C_{P 0}=5 \mathrm{mg} \cdot \mathrm{cm}^{-3}\right)$.

means the size of mass transfer resistance at the interface of packaging and food. Mass transfer resistance is inversely proportional to the mass transfer coefficient. It can be seen from Figures 17 and 18 that mass transfer coefficient has a significant influence on the release of active ingredient. The amount of active ingredient releasing from inner layer to food

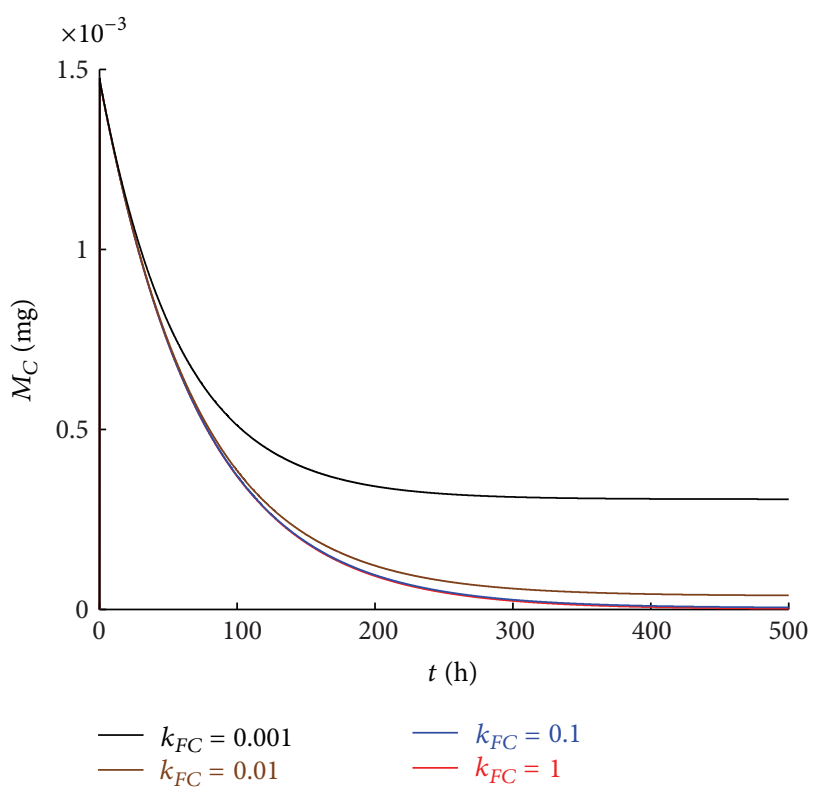

FIGURE 19: Release kinetics of active ingredient into inner layer for various $k_{F C}\left(l_{1}=48 \mu \mathrm{m}, l_{2}=16 \mu \mathrm{m}, k_{C P}=0.2, A=1 \mathrm{~cm}^{2}\right.$, and $\left.C_{P 0}=5 \mathrm{mg} \cdot \mathrm{cm}^{-3}\right)$.

increases; at the same time the amount of active ingredient remaining in the inner layer decreases with the increase of $h_{m}$, namely, the decrease of mass transfer resistance.

3.6. Release Kinetics of Active Ingredient into Inner Layer and Food for Various $k_{F C}$. The definition of $k_{F C}$ is the ratio of the concentration of active agent in food to the concentration of the active agent in inner layer at release equilibrium. At a certain extent, it means the accumulated consumption of active ingredient in food, the smaller the value, the cumulative consumption is lower; the more active ingredient is not easy to release from the packaging material to the food products. Figures 19 and 20 show that there will be more active ingredient remaining in the packaging inner layer, and the release amount of active ingredient in food decreases with the decrease of $k_{F C}$.

\section{Conclusions}

For food packaging and food system like bilayer packaging food system, the problem of release of active ingredient from outer layer to inner layer into food is very complex. As shown in this paper, different diffusivities in two-layer materials and distribution of release ingredient between two layers and between packaging material and food, mass transfer at the interface of packaging material and food should be considered. Numerical solutions taking the facts into account are obtained according to finite difference for the case of a Fickian diffusion through the packaging. The theory results are expressed from several aspects. Release kinetics of active ingredient into inner layer and food for various values of $k_{C P}$ and profiles of active ingredient concentration through the packaging for various values of $k_{C P}$, release kinetics 


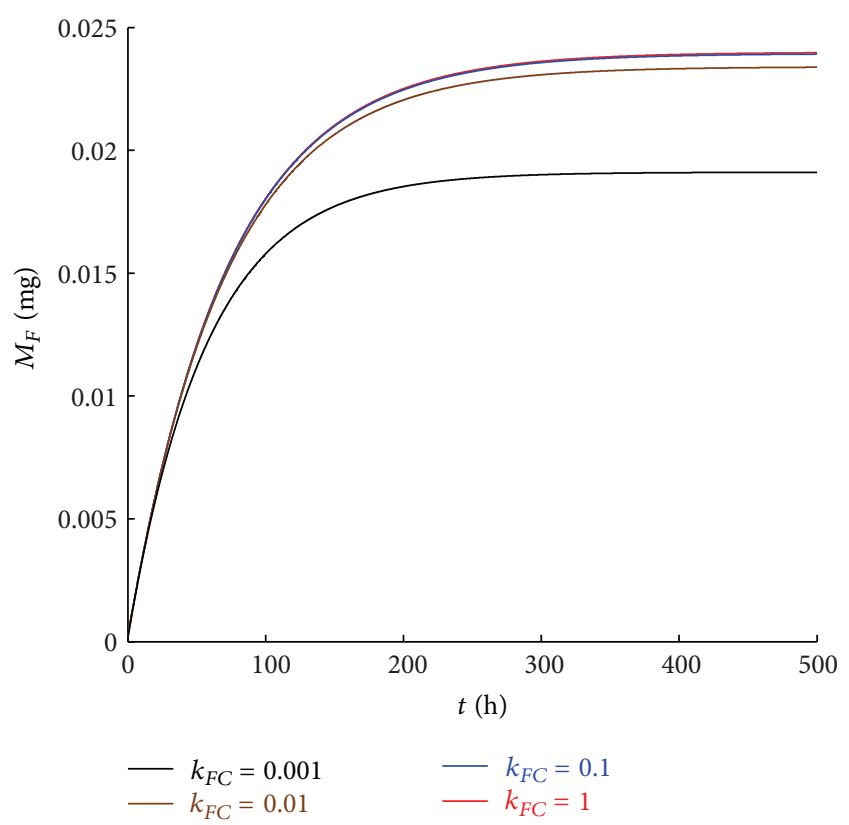

FIGURE 20: Release kinetics of active ingredient into food for various $k_{F C}\left(l_{1}=48 \mu \mathrm{m}, l_{2}=16 \mu \mathrm{m}, k_{C P}=0.2, A=1 \mathrm{~cm}^{2}, C_{P 0}=\right.$ $\left.5 \mathrm{mg} \cdot \mathrm{cm}^{-3}\right)$.

of active ingredient into inner layer and food for various thicknesses of outer layer and inner layer, release kinetics of active ingredient into inner layer and food for various $C_{P 0}$, release kinetics of active ingredient into inner layer and food for various $D_{P}$ and $D_{C}$, release kinetics of active ingredient into inner layer and food for various $h_{m}$, and release kinetics of active ingredient into inner layer and food for various $k_{F C}$ are studied for the bi-layer packaging food system. The corresponding conclusions and analysis are also given.

\section{Acknowledgments}

The authors acknowledge the support of this research by the Opening Fund of Key Laboratory of Product Packaging and Logistics of Guangdong Higher Education Institutes at Jinan University (D.10-0109-11-014) and Shanghai Young College Teacher Training-funded Projects (B.37-0109-11-003) and Shanghai University Innovation Fund (A.10-0109-12-009).

\section{References}

[1] C. H. Lee, D. S. An, S. C. Lee, H. J. Park, and D. S. Lee, "A coating for use as an antimicrobial and antioxidative packaging material incorporating nisin and $\alpha$-tocopherol," Journal of Food Engineering, vol. 62, no. 4, pp. 323-329, 2004.

[2] G. G. Buonocore, M. A. Del Nobile, A. Panizza, M. R. Corbo, and L. Nicolais, "A general approach to describe the antimicrobial agent release from highly swellable films intended for food packaging applications," Journal of Controlled Release, vol. 90, no. 1, pp. 97-107, 2003.

[3] P. Appendini and J. H. Hotchkiss, "Review of antimicrobial food packaging," Innovative Food Science and Emerging Technologies, vol. 3, no. 2, pp. 113-126, 2002.
[4] E. Mascheroni, V. Guillard, E. Gastaldi, N. Gontard, and P. Chalier, "Anti-microbial effectiveness of relative humiditycontrolled carvacrol release from wheat gluten/montmorillonite coated papers," Food Control, vol. 22, no. 10, pp. 1582-1591, 2011.

[5] M. Uz and S. A. Altinkaya, "Development of mono and multilayer antimicrobial food packaging materials for controlled release of potassium sorbate," LWT-Food Science and Technology, vol. 44, no. 10, pp. 2302-2309, 2011.

[6] K. K. Kuorwel, M. J. Cran, K. Sonneveld, J. Miltz, and S. W. Bigger, "Migration of antimicrobial agents from starch-based films into a food simulant," LWT-Food Science and Technology, vol. 50, no. 2, pp. 432-438, 2013.

[7] Ç. Mecitoğlu, A. Yemenicioğlu, A. Arslanoğlu, Z. S. Elmaci, F. Korel, and A. E. Çetin, "Incorporation of partially purified hen egg white lysozyme into zein films for antimicrobial food packaging," Food Research International, vol. 39, no. 1, pp. 12-21, 2006.

[8] S. Gemili, A. Yemenicioğlu, and S. A. Altinkaya, "Development of cellulose acetate based antimicrobial food packaging materials for controlled release of lysozyme," Journal of Food Engineering, vol. 90, no. 4, pp. 453-462, 2009.

[9] E. Mascheroni, P. Chalier, N. Gontard, and E. Gastaldi, "Designing of a wheat gluten/montmorillonite based system as carvacrol carrier: rheological and structural properties," Food Hydrocolloids, vol. 24, no. 4, pp. 406-413, 2010.

[10] M. Ramos, A. Jiménez, M. Peltzer, and M. C. Garrigós, "Characterization and antimicrobial activity studies of polypropylene films with carvacrol and thymol for active packaging," Journal of Food Engineering, vol. 109, no. 3, pp. 513-519, 2012.

[11] C. Pires, C. Ramos, B. Teixeira, I. Batista, M. L. Nunes, and A. Marques, "Hake proteins edibile films incorporated with essential oils: physical mechanical, antioxidant and antibacterial properties," Food Hydrocolloids, vol. 30, no. 1, pp. 224-231, 2013.

[12] A. Balasubramanian, D. S. Lee, M. L. Chikindas, and K. L. Yam, "Effect of Nisin's controlled release on microbial growth as modeled for Micrococcus luteus," Probiotics and Antimicrobial Proteins, vol. 3, no. 2, pp. 113-118, 2011.

[13] A. C. K. Bierhalz, M. A. da Silva, and T. G. Kieckbusch, "Natamycin release from alginate/pectin films for food packaging applications," Journal of Food Engineering, vol. 110, no. 1, pp. 18-25, 2012.

[14] Z. W. Wang, X. L. Huang, and C. Y. Hu, "A systematic study on the stability of UV ink photoinitiators in food simulants using GC," Packaging Technology and Science, vol. 22, no. 3, pp. 151159, 2009.

[15] Z. W. Wang, P. L. Wang, and C. Y. Hu, "Molecular dynamics simulation on diffusion of 13 kinds of small molecules in polyethylene terephthalate," Packaging Technology and Science, vol. 23, no. 8, pp. 457-469, 2010.

[16] X. L. Huang, Z. W. Wang, C. Y. Hu, Y. Zhu, and J. Wang, "Factors affecting migration of contaminants from paper through polymer coating into food simulants," Packaging Technology and Science, vol. 26, supplement 1, pp. 23-31, 2013.

[17] M. Chen, Z. W. Wang, C. Y. Hu, and J. L. Wang, "Effects of temperature on release of eugenol and isoeugenol from soy protein isolate films into simulated fatty food," Packaging Technology and Science, vol. 25, no. 8, pp. 485-492, 2012.

[18] C. Y. Hu, M. Chen, and Z. W. Wang, "Release of thymol, cinnamaldehyde and vanillin from soy protein isolate films into olive oil," Packaging Technology and Science, vol. 25, no. 2, pp. 97-106, 2012. 
[19] M. A. D. Nobile, A. Conte, A. L. Incoronato, and O. Panza, "Antimicrobial efficacy and release kinetics of thymol from zein films," Journal of Food Engineering, vol. 89, no. 1, pp. 57-63, 2008.

[20] X. Chen, D. S. Lee, X. Zhu, and K. L. Yam, "Release kinetics of tocopherol and quercetin from binary antioxidant controlledrelease packaging films," Journal of Agricultural and Food Chemistry, vol. 60, no. 13, pp. 3492-3497, 2012.

[21] M. Mastromatteo, G. Barbuzzi, A. Conte, and M. A. Del Nobile, "Controlled release of thymol from zein based film," Innovative Food Science and Emerging Technologies, vol. 10, no. 2, pp. 222227, 2009.

[22] J. K. Han, S. E. Selke, T. W. Downes, and B. R. Harte, "Application of a computer model to evaluate the ability of plastics to act as functional barriers," Packaging Technology and Science, vol. 16, no. 3, pp. 107-118, 2003.

[23] A. Perou, S. Laoubi, and J. M. Vergnaud, "Model for transfer of contaminant during the coextrusion of three-layer food package with a recycled polymer. Effect on the time of protection of the food of the relative thicknesses of the layers," Journal of Applied Polymer Science, vol. 73, no. 10, pp. 1939-1948, 1999.

[24] Z. Z. Sun, "A second-order difference scheme for a model of oil deposits," Acta Mathematicae Applicatae Sinica, vol. 20, no. 4, pp. 551-558, 1997.

[25] Z. Z. Sun, "A second-order accurate difference scheme for the hyperbolic problem with concentrated data," in Numerical Analysis and Its Applications 2008, S. Margenov, L. G. Vulkov, and J. Wasniewski, Eds., vol. 5434 of Lecture Notes in Computer Science, pp. 556-563, Springer, Berlin, Germany, 2009. 


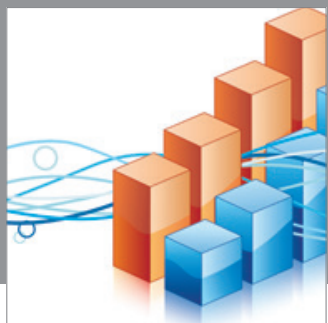

Advances in

Operations Research

mansans

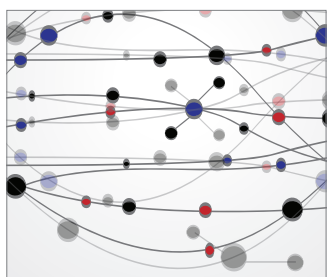

The Scientific World Journal
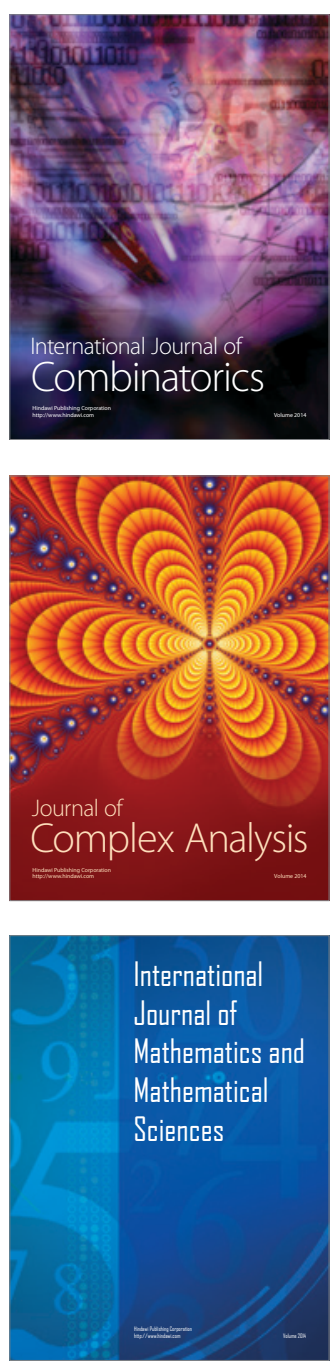
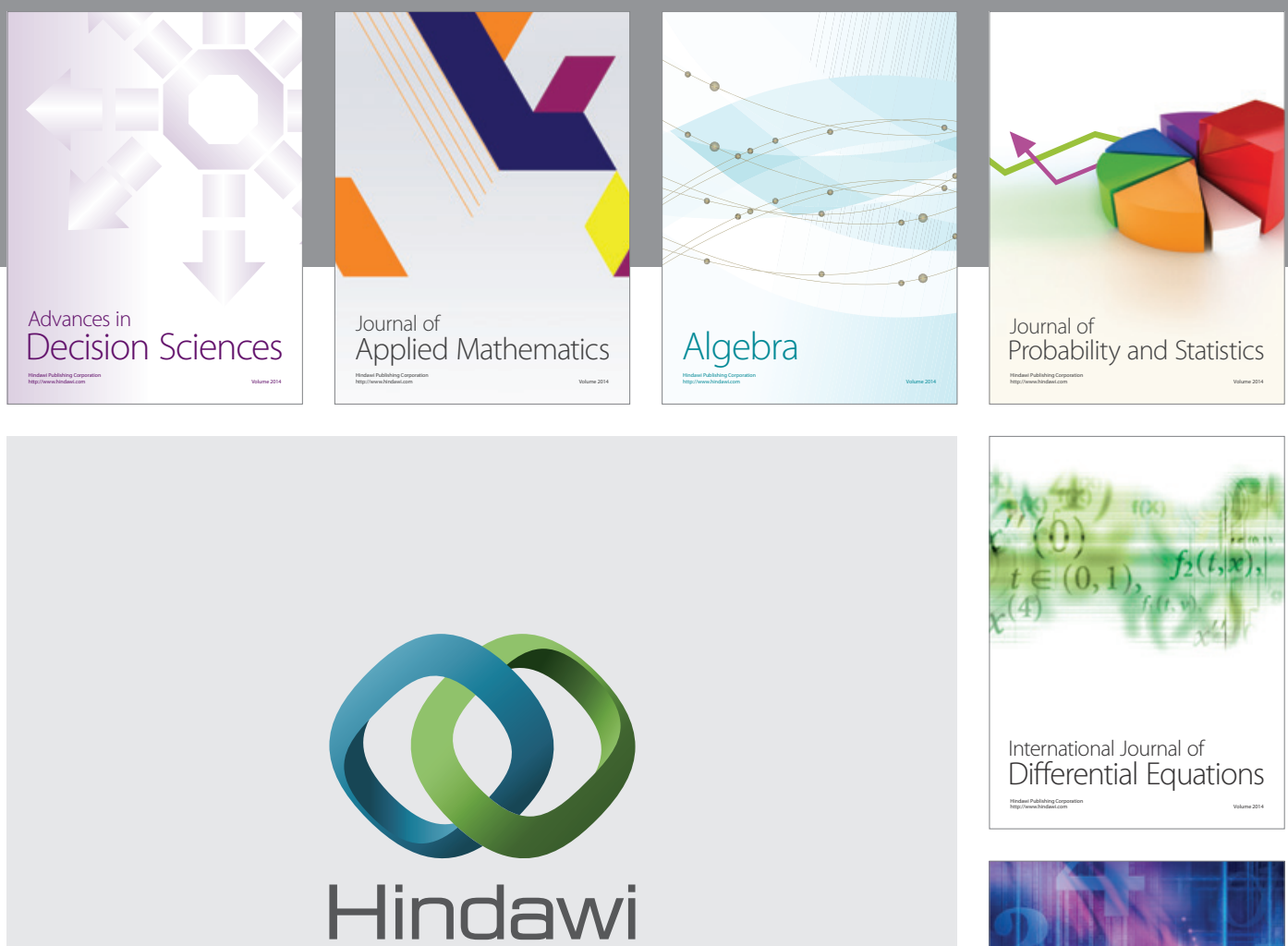

Submit your manuscripts at http://www.hindawi.com
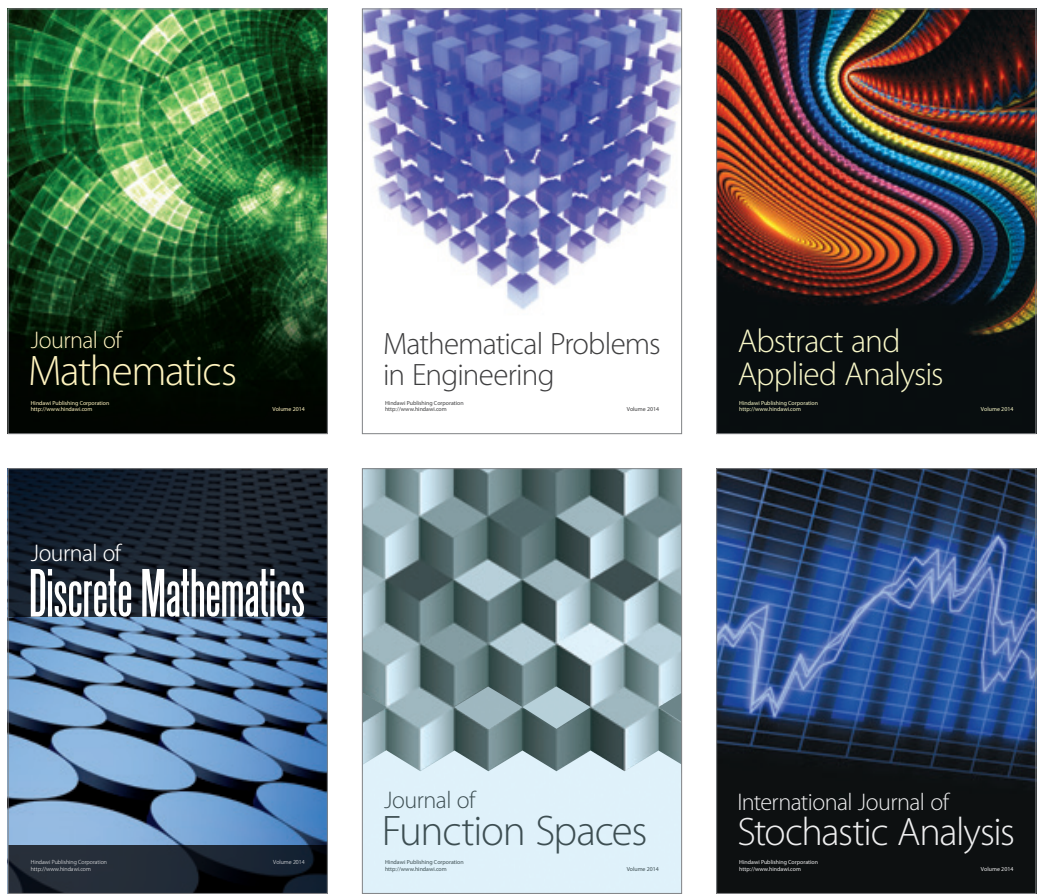

Journal of

Function Spaces

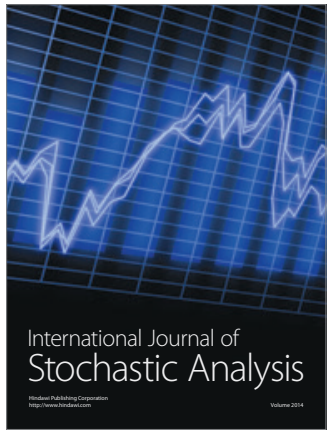

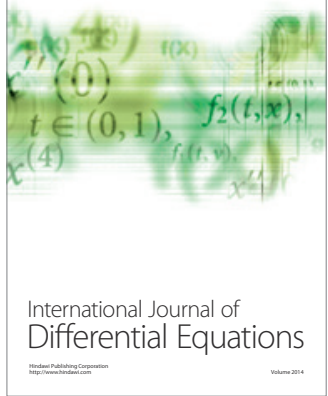
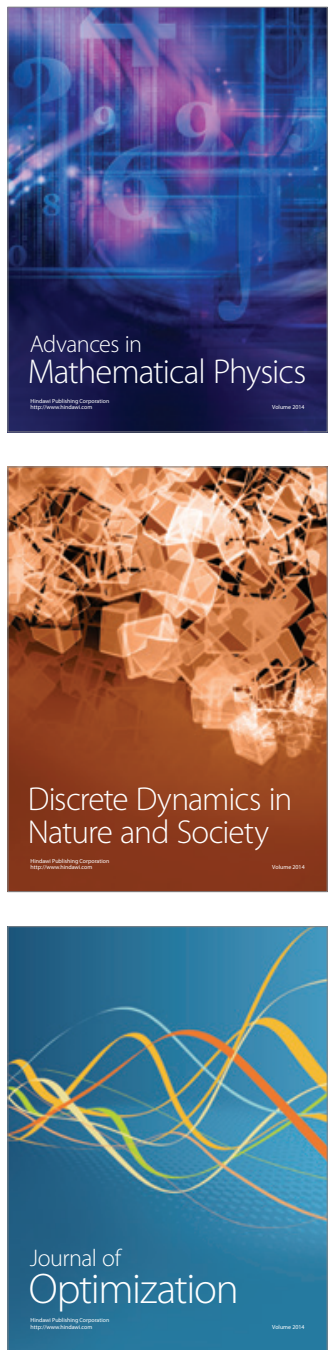